\title{
Optimal Timing of Cerebral MRI in Preterm Infants to Predict Long-Term Neurodevelopmental Outcome: A Systematic Review
}

\author{
A. Plaisier, P. Govaert, M.H. Lequin, and J. Dudink
}

\begin{abstract}
SUMMARY: Advances in neonatal neuroimaging have improved detection of preterm brain injury responsible for abnormal neuromotor and cognitive development. Increasingly sophisticated MR imaging setups allow scanning during early preterm life. In this review, we investigated how brain MR imaging in preterm infants should be timed to best predict long-term outcome. Given the strong evidence that structural brain abnormalities are related to long-term neurodevelopment, MR imaging should preferably be performed at term-equivalent age. Early MR imaging is promising because it can guide early intervention studies and is indispensable in research on preterm brain injury.
\end{abstract}

ABBREVIATIONS: DEHSI = diffuse excessive high signal intensity; $\mathrm{FA}=$ fractional anisotropy; $\mathrm{PLIC}=$ posterior limb of the internal capsule; $\mathrm{PMA}=$ postmenstrual age; $\mathrm{PWML}=$ punctate white matter lesions

$\mathbf{P}$ reterm birth with subsequent brain injury is an increasing public health concern. Advances in neonatal intensive care have significantly improved survival rates among very-low-birthweight infants, but survivors are still at considerable risk to develop cognitive, behavioral, neurosensory, and motor disabilities. ${ }^{1-5}$ The most common preterm brain injury patterns are the following: WM injury; germinal matrix-intraventricular hemorrhage and its correlates; and posthemorrhagic ventricular dilation and periventricular hemorrhagic venous infarction (Fig 1). Cystic periventricular leukomalacia is seen less often now, and diffuse noncystic types of WM injury, including punctate WM lesions and diffuse excessive high signal intensity, are therefore most frequent $^{6-10}$ and the leading cause of disturbed brain growth, connectivity, and functionality. ${ }^{11-13}$

Although MR imaging is superior to cranial sonography in detecting diffuse WM injury, ${ }^{14-17}$ structural MR imaging studies fail to precisely predict outcome $e^{6,8,18}$ because conventional MR imaging is not sensitive enough to measure changes in microstructure. ${ }^{19}$ However, advanced MR imaging acquisition sequences and postprocessing techniques, such as DTI, volumetric

From the Division of Neonatology (A.P., P.G., J.D.), Department of Pediatrics, and Division of Pediatric Radiology (A.P., M.H.L., J.D.), Department of Radiology, Erasmus Medical Center-Sophia, Rotterdam, the Netherlands; and Department of Pediatrics (P.G.), Koningin Paola Children's Hospital, Antwerp, Belgium.

Please address correspondence to Annemarie Plaisier, MD, Division of Neonatology, Department of Pediatrics, Erasmus Medical Center-Sophia, Dr Molewaterplein 60, 3015 GJ Rotterdam, Netherlands; e-mail: a.plaisier.1@erasmusmc.nl

- Indicates open access to non-subscribers at www.ajnr.org

三 Indicates article with supplemental on-line table.

http://dx.doi.org/10.3174/ajnr.A3513

MR imaging measurements, and proton MR spectroscopy $\left({ }^{1} \mathrm{H}-\mathrm{MR}\right.$ spectroscopy), may be a solution. For example, DTI allows quantification of WM at a microstructural level by measuring the diffusion of water molecules in tissues. ${ }^{20,21}$

DTI studies have shown increasing fractional anisotropy and decreasing $\mathrm{ADC}$ during brain maturation, which is ascribed to the decreased water content and increased WM complexity due to myelination. ${ }^{20,22}$ Deviations from these developmental trends are considered diagnostic of perinatal WM injury. ${ }^{23-25}$

WM injury in preterm infants has been related to significantly reduced brain volume, ${ }^{26,27}$ but brain growth in extremely preterm infants may also be disturbed in the absence of evident WM abnormalities. Volumes of brain regions and structures are correlated to perinatal complications and are inversely related to gestational age at birth. ${ }^{28,29}$ Smaller volumes are often associated with impaired neuropsychological function at a later age. ${ }^{29,30}$

Assessment of cortical folding during early brain development, with the use of postprocessing software, ${ }^{31}$ has provided insight into the underlying mechanisms of normal development, regional specialization, and functional lateralization. ${ }^{32,33}$ Anomalous cortical folding, demonstrated in preterm infants, has been proposed as an early biomarker of neurocognitive impairment. ${ }^{34,35}$

Metabolic integrity of tissues can be measured in vivo with ${ }^{1} \mathrm{H}-\mathrm{MR}$ spectroscopy. The NAA/Cho ratio is of special interest in neonatal neuroimaging because the ratio increases during brain maturation as an effect of synthesis by proliferating oligodendrocyte progenitor cells. ${ }^{36}$

Early MR imaging provides early biomarkers of preterm brain injury and enables early parental counseling. However, systematic 


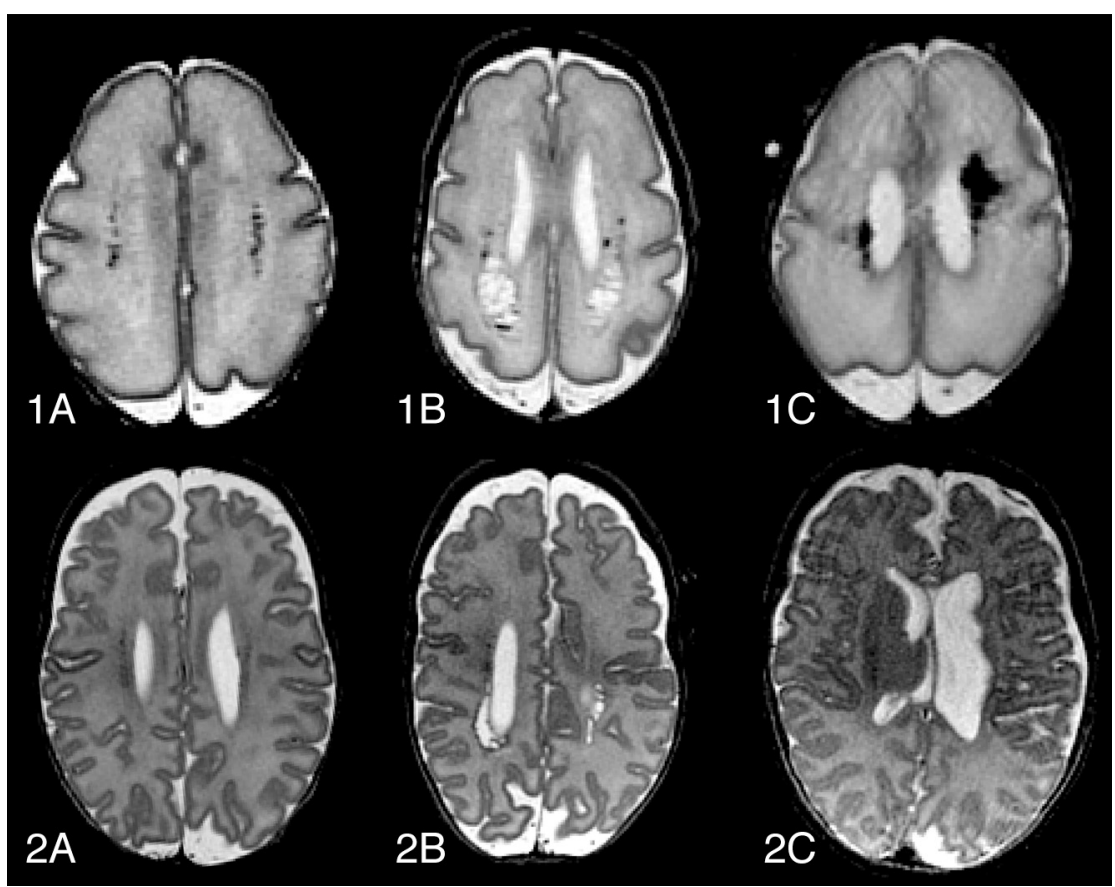

FIG 1. Evolution of common types of preterm brain injury, at 30 weeks' postmenstrual age (1) and at term-equivalent age (2). Transversal T2-FSE images of punctate white matter lesions $(A)$, periventricular leukomalacia $(B)$, and periventricular hemorrhagic venous infarction $(C)$. Note that images $2 B$ and $2 C$ are slightly oblique.

use of such MR imaging has its limitations due to hemodynamic, respiratory, and thermodynamic instability seen in most preterm infants. ${ }^{37}$ Moreover, technical aspects like smaller heads result in lower SNR. ${ }^{38}$ As in most studies obtained at term-equivalent age, ${ }^{18,30}$ less is known about the value of scanning at a lower postmenstrual age. Furthermore, brain injury can also occur in the late preterm period. MR imaging at term has the disadvantage of parents and caregivers not being fully informed until their child reaches term age. Furthermore, logistic issues may emerge in centers where infants are transferred to other hospitals once certain criteria are met.

Because there seems to be no consensus on the optimal timing of MR imaging, we reviewed the literature on the prediction of neurodevelopmental outcome with the use of brain MR imaging performed at either early preterm or term age.

\section{MATERIALS AND METHODS}

The Embase, MEDLINE OvidSP, Cochrane, and PubMed databases were systematically searched for relevant articles published between 1979 and November 2012. The strategy included synonyms and combinations of the following keywords: "prematurity, " "neuroimaging, " "brain, " and "MR imaging " (full research strategy is available on-line). The search was limited to human research that involved original patient data, and only articles written in English were included.

Studies were eligible under the following conditions: 1 ) they included preterm infants born at $<32$ week' gestation, 2) MR imaging was performed in the neonatal period, and 3) neurodevelopmental outcome was linked to MR imaging findings. To avoid large variations in MR imaging determinants, we only in- cluded structural MR imaging studies if they evaluated the findings according to a reproducible classification.

The initial search resulted in $2104 \mathrm{ci}-$ tations. Two reviewers (A.P., J.D.) screened all abstracts of these citations for relevance and reached a consensus after discussion in case of disagreement. Sixty-two articles were incorporated in this review. In the "Results" section, we present findings according to type of MR imaging technique: conventional structural MR imaging, such as T1- and T2-weighted scans, DTI, volumetric MR imaging, and proton MR spectroscopy. Further classification was based on the timing of MR imaging: serial, before 35 weeks', or after 35 weeks' PMA.

\section{RESULTS}

\section{Conventional Structural MR Imaging}

Serial MR Imaging. Three serial neuroimaging studies correlated injury to outcome (Table 1). One was a prospective consecutive MR imaging study by Dyet et $\mathrm{al},{ }^{8}$ regarding $327 \mathrm{MR}$ imaging scans of 119 preterm infants. Only major destructive cerebral and cerebellar lesions seen at the initial scan within 2 days after birth were related to poorer neurodevelopmental outcome. DEHSI and posthemorrhagic ventricular dilation at term-equivalent age were significantly related to adverse outcome. Isolated hemorrhage or PWML did not seem to predict adverse neurodevelopmental outcome. The second, by Miller et al, ${ }^{39}$ demonstrated that moderately severe abnormalities, such as WM injury, ventriculomegaly, and intraventricular hemorrhage on early scans were associated with adverse neurodevelopmental outcome as strongly (or even more strongly) as abnormalities on the term-equivalent scans: The relative risk was 5.6 and 5.3, respectively. The third, a large serial MR imaging study by Tam et $\mathrm{al}^{40}{ }^{40}$ demonstrated that not only large but also small cerebellar hemorrhages, not detected on cranial sonography, were associated with abnormal neurologic examination at 3-6 years of age. The presence of these small cerebellar hemorrhages was associated with a 5.0 odds ratio of abnormal neurologic examination findings at a mean age of 4.8 years.

MR Imaging at $\leq 35$ Weeks' PMA. The presence of cystic periventricular leukomalacia and cerebellar hemorrhage at 35 weeks' gestation was significantly correlated to abnormal neurologic examination findings at 30 months in a retrospective neuroimaging study by Cornette et al. ${ }^{41}$ Isolated PWML was not correlated to abnormal neurodevelopmental outcome at 30 months of age (Table 2).

MR Imaging at >35 Weeks' PMA. Twenty-six studies correlated brain injury or conventional MR imaging at 35 weeks' PMA with outcome (On-line Table). 
Table 1: Details of included serial MRI studies

\begin{tabular}{|c|c|c|c|c|}
\hline MRI Modality & & Population & $\begin{array}{l}\text { Timing of } \\
\text { MRI (wk) }\end{array}$ & Main Findings \\
\hline \multirow[t]{3}{*}{$\begin{array}{l}\text { Structural } \\
\text { conventional }\end{array}$} & Dyet et $\mathrm{al}^{8}$ & 119 Infants $<30$ wks & Serial & $\begin{array}{l}\text { Abnormal outcome a at } 18 \text { mos was related to major } \\
\text { destructive lesions, DEHSI, cerebellar hemorrhage, and } \\
\text { posthemorrhagic ventricular dilation }\end{array}$ \\
\hline & Miller et $\mathrm{al}^{39}$ & 89 Infants $<34$ wks & $32+37$ & $\begin{array}{l}\text { Abnormal outcome at } 18 \text { mos }^{b} \text { was related to severity of } \\
\text { WM injury, ventriculomegaly, and intraventricular } \\
\text { hemorrhage on first }(R R, 5.6) \text { and second (RR, 5.3) MRIs }\end{array}$ \\
\hline & Tam et al ${ }^{40}$ & 131 Infants $<34$ wks & $32+37$ & $\begin{array}{l}\text { Abnormal neurologic examination findings at } 4.8 \text { yrs } \\
\text { were related to large and small cerebellar hemorrhage; } \\
\text { OR for small hemorrhage was } 5.0\end{array}$ \\
\hline \multirow[t]{2}{*}{ DTI } & Drobyshevsky et al ${ }^{70}$ & 24 Infants $<32$ wks & $30+36$ & $\begin{array}{l}\mathrm{PDI}^{\mathrm{b}} \text { at } 24 \text { mos correlated to FA of the PLIC at } 30 \text { wks } \\
(r=0.55), \text { faster increase of FA/wk in internal capsule } \\
(r=-0.63) \text {, and occipital WM }(r=-0.59)\end{array}$ \\
\hline & Glass et $\mathrm{a}^{71}$ & 9 Infants $<34$ wks & $33+38$ & $\begin{array}{l}\text { FA of the optic radiation was correlated with visual- } \\
\text { evoked-potential amplitude }(r=0.7) \text { at } 10.5 \text { mos }\end{array}$ \\
\hline \multirow[t]{2}{*}{ Volumetric } & Dubois et $\mathrm{a}^{81}$ & 45 Infants $<36$ wks & $32+41$ & $\begin{array}{l}\text { Functional assessment at term was associated with inner } \\
\text { cortical surface and sulcation index }\end{array}$ \\
\hline & $\begin{array}{l}\text { Kapellou et al }{ }^{82} \\
\text { Rathbone et } \mathrm{al}^{83}\end{array}$ & 119 Infants $<30$ wks & Serial & $\begin{array}{l}\text { Growth of the cortical surface area was related to } \\
\text { neurodevelopmental outcome }{ }^{a} \text { at } 24 \text { mos and full- } \\
\text { scale IQ at } 6 \text { yrs }\end{array}$ \\
\hline
\end{tabular}

Note:- RR indicates relative risk; OR, odds ratio; PDI, Psychomotor Development Index.

${ }^{a}$ Griffiths Mental Developmental Scales.

${ }^{\mathrm{b}}$ Bayley Scales of Infant Development.

Table 2: Details of included MRI studies, scanned at $\leq 35$ weeks' postmenstrual age

\begin{tabular}{|c|c|c|c|c|}
\hline MRI Modality & & Population & $\begin{array}{l}\text { Timing of } \\
\text { MRI (wk) }\end{array}$ & Main Findings \\
\hline Structural conventional & Cornette et al ${ }^{41}$ & 50 Infants $<37$ wks & 35 & $\begin{array}{l}\text { Major cerebral abnormalities were correlated to } \\
\text { abnormal outcome at } 30 \text { mos; isolated PWML } \\
\text { were not related to neurodevelopmental } \\
\text { impairment }\end{array}$ \\
\hline Volumetric & Badr et $\mathrm{al}^{84}$ & 59 Infants $<37$ wks & 31 & $\begin{array}{l}\text { WM volume was correlated significantly to } \mathrm{PDI}^{\mathrm{a}} \\
(r=0.29) \text { and } \mathrm{MDI}^{\mathrm{a}}(r=0.31) \text { at } 18 \mathrm{mos}\end{array}$ \\
\hline
\end{tabular}

Note:- PDI indicates Psychomotor Development Index; MDI, Mental Development Index.

a Bayley Scales of Infant Development.

The impact of overt WM lesions at term on neurodevelopment has been extensively investigated. The severity of WM abnormalities is often assessed according to a comprehensive scoring system ${ }^{15}$ and is assumed to be directly associated with the incidence of neuromotor impairment until 5 years of age $e^{9,10,15-17,42-49}$ and to be inversely correlated to the Bayley scales $^{50}$ until 30 months ${ }^{15,16,43,51-54}$ and cognitive performance until 9 years of age. ${ }^{55-60}$ The presence of WM injury has an odds ratio of 8.3 for low full-scale intelligence quotient $(\mathrm{IQ}<70) .{ }^{59}$ Moderate-to-severe WM abnormalities highly predict severe motor delay; odds ratios up to 10.0 and positive predictive values up to $100 \%$ have been demonstrated. ${ }^{15,42,44,45,52,59}$

The association between subtle diffuse WM injury and neurodevelopmental outcome is not clear. ${ }^{61}$ Some research groups demonstrated a significant association between PWML and impaired neurodevelopmental outcome, ${ }^{10,46,62}$ whereas others suggested the contrary, provided that no other major lesions were observed. ${ }^{8,52}$ DEHSI was associated with adverse outcome in a large serial imaging study by Dyet et al, ${ }^{8}$ but others could not confirm this finding. ${ }^{10,42,51,59,62,63}$ The lack of clarity is thought to be due to the absence of objective definitions for these patterns of brain injury ${ }^{24,48,64}$ and raises the importance of objective assessment of diffuse WM injury.

Extensive intraventricular hemorrhage and venous infarc- tions, according to Papile et al, ${ }^{65}$ are associated with neurodevelopmental impairment. ${ }^{16,17,48,53}$ Posthemorrhagic ventricular dilation is associated with neurologic impairment until 6 years of age. ${ }^{66}$ In a study by De Vries et al, ${ }^{67}$ asymmetric myelination of the PLIC at term age in preterm infants with venous infarction seemed to be an early predictor of future hemiplegia.

Although commonly described in cranial sonographic studies, ${ }^{68}$ caudothalamic cysts were not related to cognitive and neuropsychological impairment in a MR imaging study by Lind et al. ${ }^{69}$

The impact of gray matter abnormalities remains unclear. They were significantly associated with abnormal neurobehavioral outcome at term in a study by Brown et $\mathrm{al}^{47}$ and with decreased Bayley scales at 2 years in a study by Woodward et al, ${ }^{15}$ but others ${ }^{9,59}$ found no significant relationship between injury to the cerebral gray matter and neuromotor function at term ${ }^{9}$ or cognitive outcome at 9 years of age. ${ }^{59}$

\section{Diffusion Tensor Imaging}

Serial MR Imaging. Two serial DTI studies found a significant correlation with cognitive and neurosensory outcome (Table 1). Drobyshevsky et $\mathrm{al}^{70}$ demonstrated that the Bayley performance index at 24 months was correlated with FA of the PLIC at 30 weeks 
$(r=0.55)$ and faster increase of FA per week in the internal capsule $(r=-0.63)$ and occipital WM $(r=-0.59)$. Increased FA values in the optic radiation at 33 and 37 weeks were associated with increased visual-evoked-response amplitudes at 10.5 months $(r=0.7) .{ }^{71}$ However, this may not necessarily mean that eventually visual function is better.

MR Imaging at $\leq 35$ Weeks' PMA. None of the included studies related early DTI measurements to long-term outcome.

MR Imaging at $>35$ Weeks' PMA. In a tract-based spatial statistics study by van Kooij et al, ${ }^{72}$ FA values of the corpus callosum were correlated to cognitive scores, gross motor scores were correlated with radial diffusion of the corpus callosum and internal and external capsules, and fine-motor scores were correlated to FA throughout the WM. Other DTI studies have demonstrated similar correlations: DTI parameters of the corpus callosum, PLIC, right orbital frontal cortex, and centrum semiovale were correlated to cognitive performance (On-line Table). ${ }^{73-76}$ In other studies, DTI measurements of the corpus callosum, PLIC, and corona radiata were correlated to motor function..$^{74,77-79}$ Furthermore, FA values of the optic radiation were directly correlated to visual assessment scores at termequivalent age. ${ }^{80}$

\section{Volumetric MR Imaging}

Serial MR Imaging. Three serial volumetric MR imaging studies demonstrated that early structural abnormalities are predictors of neurobehavioral outcome (Table 1 ). Dubois et $\mathrm{al}^{81}$ concluded that at term-corrected age, neurobehavioral development was significantly associated with quantitative surrogates of cortical folding. Kapellou et $\mathrm{al}^{82}$ found that the ratio between cortical surface area and cerebral volume was directly related to neurodevelopment at 24 months. The same group showed that growth of the cortical surface area was also significantly related to intelligence at 6 years: A faster growth of $0.032 \%$ per week resulted in an increase of 1 IQ point. ${ }^{83}$

MR Imaging at $\leq 35$ Weeks' PMA. Badr et $\mathrm{al}^{84}$ found that WM volume on MR imaging at a mean PMA of 31 weeks was significantly correlated to the Bayley Psychomotor Development Index $(r=0.29)$ and Mental Development Index $(r=0.31)$ at 18 months (Table 2).

MR Imaging at $>35$ Weeks' PMA. Volumetric MR imaging studies in preterm infants with neurodevelopmental impairment have demonstrated significantly smaller total brain volume ${ }^{54,66,85}$ and volume of several cerebral structures or regions, including the cerebellum, ${ }^{66,86-89}$ total WM, ${ }^{90}$ total $^{28,91}$ and deep ${ }^{66,76}$ gray matter, occipital lobes, ${ }^{92}$ hippocampus, ${ }^{93,94}$ and brain stem, ${ }^{95}$ as well as significantly larger ventricles (On-line Table). ${ }^{28,96}$ These findings were irrespective of the presence of overt brain injury. Simple linear metric assessment, such as biparietal and cerebellar diameter, on MR imaging also significantly correlated with neurocognitive function. ${ }^{97,98}$ Impaired social-emotional development at 5 years was associated with decreased hippocampal volume in girls and decreased frontal lobe growth in boys. ${ }^{75}$

\section{Proton MR Spectroscopy}

MR Imaging at $>35$ Weeks' PMA. ${ }^{1} \mathrm{H}-\mathrm{MR}$ spectroscopy is an accurate quantitative biomarker for the prediction of neurodevelopmental outcome after hypoxic-ischemic encephalopathy in term infants (On-line Table).$^{99}$ It is not clear whether this holds true for preterm infants. The cerebellar NAA/Cho ratio at term is suggested to correlate with cognitive outcome at 24 months. ${ }^{89}$ However, Gadin et $\mathrm{al}^{91}$ found no correlation between MR spectroscopy of the periventricular WM and motor development at 6 months.

\section{DISCUSSIONS}

This systematic review included 8 serial MR imaging studies, 2 MR imaging studies performed at $\leq 35$ weeks, and 52 MR imaging studies performed at $>35$ weeks. The results of these studies made clear that the extent of structural abnormalities, microstructural deviations, and global reductions in brain volumes, both at preterm and term age, is directly related to the level of neuromotor and neurocognitive performance in childhood. Involvement of WM in preterm brain injury seems paramount. Accurate assessment of WM integrity, therefore, may help predict long-term outcome in preterm infants and is one of the challenging goals in the field of neonatal neurology.

These studies do not provide clear evidence on the optimal timing of MR imaging. Although an increasing number of neuroimaging studies used early MR imaging to show that brain abnormalities are often present during early preterm life, ${ }^{22,100,101}$ only 2 of the studies linked these findings to outcome. Dyet et $\mathrm{al}^{8} \mathrm{dem}-$ onstrated that MR imaging within the first 2 days after birth was of limited additional value for predicting outcome. On the other hand, Miller et al ${ }^{39}$ reported that early MR imaging findings at 32 weeks' gestation were as reliable for predicting neurodevelopment as MR imaging findings at term age. This finding suggests that predictive MR imaging may be performed well before termequivalent age, provided it is after the first week of life.

Neonatal care would benefit from identifying brain injury early in preterm life, in terms of effective and timely parental counseling, tailored rehabilitation strategies, and better understanding of neuropathology. Currently, we have no efficacious therapy for preterm brain injury, but trials on possible neuroprotective agents, such as erythropoietin, melatonin, stem cell therapy, and magnesium sulfate are being conducted or planned for the near future. ${ }^{102,103}$ Early MR imaging could provide early biomarkers that trials could target.

Image acquisition, processing, and interpretation are not as straightforward as with conventional MR imaging, though sophisticated techniques such as DTI allow objective and quantifiable assessment of cerebral tissue. Because measurement accuracy depends on various aspects, including scanner type, hardware setup, acquisition settings, and clinical characteristics, reproducibility of the same measurements in different imaging centers is low. Furthermore, the availability of normal ADC and FA values of specific WM structures is limited. In addition, DTI is especially sensitive to image artifacts and corruption. ${ }^{104}$ Reliable conclusions can therefore only be drawn if quality assessment before postprocessing provided satisfactory data quality. In the included studies, quality assessment was often not performed. 
MR imaging is expensive and time-consuming and requires great experience and dedication to ensure patient safety ${ }^{37}$ as well as good quality data and interpretation. ${ }^{105}$ These limitations should be especially taken into account with regard to the individual clinical care for patients with normal cranial sonography findings. This technique can reliably predict some aspects of the outcome of preterm infants and allows serial neuroimaging in a fast, convenient, and less-expensive manner. ${ }^{106,107}$ Moreover, advanced applications, such as color Doppler sonography, also allow objective and quantitative brain assessment.

Several limitations of this systematic review need to be addressed. First, heterogeneity of the study populations was due to variation in age at MR imaging, acquisition settings, postprocessing methods for MR imaging evaluation and other technical aspects of MR imaging scanners, different ages at outcome measurement, and different measures of outcome. Second, follow-up periods were relatively short. Third, because the search was restricted to articles in the English language, possible relevant studies might not have been included.

\section{CONCLUSIONS}

MR imaging remains an outstanding method to predict longterm neurodevelopmental outcome, and cerebral MR imaging should be part of standard clinical care for preterm infants. Early MR imaging allows timely parental counseling, targeting of rehabilitation strategies, and availability of early biomarkers. However, the individual prognostic information provided by early scanning remains inferior to that provided by term scanning. As long as the correlation of brain injury from early MR imaging with outcome is not clear, we would argue that standard MR imaging should preferably be performed at term-equivalent age. On the other hand, early MR imaging yields important information about the pathogenesis of preterm brain injury and therefore is indispensable in research on preterm brain injury.

\section{ACKNOWLEDGMENTS}

We thank Wichor Bramer from the Erasmus Medical Center medical library for his help in devising the search strategy.

\section{REFERENCES}

1. Saigal S, Doyle LW. An overview of mortality and sequelae of preterm birth from infancy to adulthood. Lancet 2008;371:261-69

2. Bhutta AT, Cleves MA, Casey PH, et al. Cognitive and behavioral outcomes of school-aged children who were born preterm: a metaanalysis. JAMA 2002;288:728-37

3. Larroque B, Ancel PY, Marret S, et al. Neurodevelopmental disabilities and special care of 5-year-old children born before 33 weeks of gestation (the EPIPAGE study): a longitudinal cohort study. Lancet 2008;371:813-20

4. Marlow N, Wolke D, Bracewell MA, et al. Neurologic and developmental disability at six years of age after extremely preterm birth. N Engl J Med 2005;352:9-19

5. Williams J, Lee KJ, Anderson PJ. Prevalence of motor-skill impairment in preterm children who do not develop cerebral palsy: a systematic review. Dev Med Child Neurol 2010;52:232-37

6. Rutherford MA, Supramaniam V, Ederies A, et al. Magnetic resonance imaging of white matter diseases of prematurity. Neuroradiology 2010;52:505-21

7. Inder TE, Wells SJ, Mogridge NB, et al. Defining the nature of the cerebral abnormalities in the premature infant: a qualitative magnetic resonance imaging study. J Pediatr 2003;143:171-79

8. Dyet LE, Kennea N, Counsell SJ, et al. Natural history of brain lesions in extremely preterm infants studied with serial magnetic resonance imaging from birth and neurodevelopmental assessment. Pediatrics 2006;118:536-48

9. Spittle AJ, Brown NC, Doyle LW, et al. Quality of general movements is related to white matter pathology in very preterm infants. Pediatrics 2008;121:e1184-89

10. Jeon TY, Kim JH, Yoo SY, et al. Neurodevelopmental outcomes in preterm infants: comparison of infants with and without diffuse excessive high signal intensity on MR images at near-term-equivalent age. Radiology 2012;263:518-26

11. Volpe JJ. Brain injury in premature infants: a complex amalgam of destructive and developmental disturbances. Lancet Neurol 2009;8:110-24

12. Khwaja O, Volpe JJ. Pathogenesis of cerebral white matter injury of prematurity. Arch Dis Child Fetal Neonatal Ed 2008;93:F153-61

13. Hüppi PS, Murphy B, Maier SE, et al. Microstructural brain development after perinatal cerebral white matter injury assessed by diffusion tensor magnetic resonance imaging. Pediatrics 2001;107:455-60

14. Inder TE, Anderson NJ, Spencer C, et al. White matter injury in the premature infant: a comparison between serial cranial sonographic and MR findings at term. AJNR Am J Neuroradiol 2003;24:805-09

15. Woodward LJ, Anderson PJ, Austin NC, et al. Neonatal MRI to predict neurodevelopmental outcomes in preterm infants. $N$ Engl J Med 2006;355:685-94

16. Mirmiran M, Barnes PD, Keller K, et al. Neonatal brain magnetic resonance imaging before discharge is better than serial cranial ultrasound in predicting cerebral palsy in very low birth weight preterm infants. Pediatrics 2004;114:992-98

17. Valkama AM, Paakko EL, Vainionpaa LK, et al. Magnetic resonance imaging at term and neuromotor outcome in preterm infants. Acta Paediatr 2000;89:348-55

18. Ment LR, Hirtz D, Huppi PS. Imaging biomarkers of outcome in the developing preterm brain. Lancet Neurol 2009;8:1042-55

19. Counsell SJ, Rutherford MA, Cowan FM, et al. Magnetic resonance imaging of preterm brain injury. Arch Dis Child Fetal Neonatal Ed 2003;88:F269-74

20. Hüppi PS, Dubois J. Diffusion tensor imaging of brain development. Semin Fetal Neonatal Med 2006;11:489-97

21. Jones DK. Studying connections in the living human brain with diffusion MRI. Cortex 2008;44:936-52

22. Dudink J, Lequin M, van Pul C, et al. Fractional anisotropy in white matter tracts of very-low-birth-weight infants. Pediatr Radiol 2007;37:1216-23

23. Miller SP, Vigneron DB, Henry RG, et al. Serial quantitative diffusion tensor MRI of the premature brain: development in newborns with and without injury. J Magn Reson Imaging 2002;16:621-32

24. Counsell SJ, Allsop JM, Harrison MC, et al. Diffusion-weighted imaging of the brain in preterm infants with focal and diffuse white matter abnormality. Pediatrics 2003;112:1-7

25. Counsell SJ, Shen Y, Boardman JP, et al. Axial and radial diffusivity in preterm infants who have diffuse white matter changes on magnetic resonance imaging at term-equivalent age. Pediatrics 2006; 117:376-86

26. Inder TE, Huppi PS, Warfield S, et al. Periventricular white matter injury in the premature infant is followed by reduced cerebral cortical gray matter volume at term. Ann Neurol 1999;46:755-60

27. Thompson DK, Warfield SK, Carlin JB, et al. Perinatal risk factors altering regional brain structure in the preterm infant. Brain 2007;130:667-77

28. Inder TE, Warfield SK, Wang $\mathrm{H}$, et al. Abnormal cerebral structure is present at term in premature infants. Pediatrics 2005;115:286-94

29. Keunen K, Kersbergen KJ, Groenendaal F, et al. Brain tissue vol- 
umes in preterm infants: prematurity, perinatal risk factors and neurodevelopmental outcome - a systematic review. J Matern Fetal Neonatal Med 2012;25(suppl 1):89-100

30. Mathur A, Inder T. Magnetic resonance imaging: insights into brain injury and outcomes in premature infants. J Commun Disord 2009;42:248-55

31. Dubois J, Benders M, Cachia A, et al. Mapping the early cortical folding process in the preterm newborn brain. Cereb Cortex 2008; 18:1444-54

32. Dubois J, Benders M, Lazeyras F, et al. Structural asymmetries of perisylvian regions in the preterm newborn. Neuroimage 2010;52:32-42

33. Dubois J, Hertz-Pannier L, Cachia A, et al. Structural asymmetries in the infant language and sensori-motor networks. Cereb Cortex 2009; 19:414-23

34. Ajayi-Obe M, Saeed N, Cowan FM, et al. Reduced development of cerebral cortex in extremely preterm infants. Lancet 2000;356:1162-63

35. Hüppi PS, Schuknecht B, Boesch C, et al. Structural and neurobehavioral delay in postnatal brain development of preterm infants. Pediatr Res 1996;39:895-901

36. Hüppi PS, Lazeyras F. Proton magnetic resonance spectroscopy ((1)H-MRS) in neonatal brain injury. Pediatr Res 2001;49:317-20

37. Plaisier A, Raets MM, van der Starre C, et al. Safety of routine early MRI in preterm infants. Pediatr Radiol 2012;42:1205-11

38. Hillenbrand CM, Reykowski A. MR imaging of the newborn: a technical perspective. Magn Reson Imaging Clin N Am 2012; 20:63-79

39. Miller SP, Ferriero DM, Leonard C, et al. Early brain injury in premature newborns detected with magnetic resonance imaging is associated with adverse early neurodevelopmental outcome. $\mathrm{JPe}$ diatr 2005;147:609-16

40. Tam EW, Rosenbluth G, Rogers EE, et al. Cerebellar hemorrhage on magnetic resonance imaging in preterm newborns associated with abnormal neurologic outcome. J Pediatr 2011;158:245-50

41. Cornette LG, Tanner SF, Ramenghi LA, et al. Magnetic resonance imaging of the infant brain: anatomical characteristics and clinical significance of punctate lesions. Arch Dis Child Fetal Neonatal Ed 2002;86:F171-77

42. Skiöld B, Vollmer B, Bohm B, et al. Neonatal magnetic resonance imaging and outcome at age $\mathbf{3 0}$ months in extremely preterm infants. J Pediatr 2012;160:559-566.e1

43. Hnatyszyn G, Cyrylowski L, Czeszynska MB, et al. The role of magnetic resonance imaging in early prediction of cerebral palsy. Turk J Pediatr 2010;52:278-84

44. Spittle AJ, Boyd RN, Inder TE, et al. Predicting motor development in very preterm infants at 12 months' corrected age: the role of qualitative magnetic resonance imaging and general movements assessments. Pediatrics 2009;123:512-17

45. Spittle AJ, Cheong J, Doyle LW, et al. Neonatal white matter abnormality predicts childhood motor impairment in very preterm children. Dev Med Child Neurol 2011;53:1000-06

46. Nanba Y, Matsui K, Aida N, et al. Magnetic resonance imaging regional $\mathrm{T} 1$ abnormalities at term accurately predict motor outcome in preterm infants. Pediatrics 2007;120:e10-e19

47. Brown NC, Inder TE, Bear MJ, et al. Neurobehavior at term and white and gray matter abnormalities in very preterm infants. $J \mathrm{Pe}$ diatr 2009;155:32-8, 38.e1

48. Aida N, Nishimura G, Hachiya $Y$, et al. MR imaging of perinatal brain damage: comparison of clinical outcome with initial and follow-up MR findings. AJNR Am J Neuroradiol 1998;19:1909-21

49. van Wezel-Meijler G, Van Der Knaap MS, Oosting J, et al. Predictive value of neonatal MRI as compared to ultrasound in premature infants with mild periventricular white matter changes. Neuropediatrics 1999;30:231-38

50. Bayley N. Bayley Scales of Infant and Toddler Development, 3rd ed. San Antonio, Texas: Harcourt Assessment; 2006

51. Hart A, Whitby E, Wilkinson S, et al. Neuro-developmental out- come at 18 months in premature infants with diffuse excessive high signal intensity on MR imaging of the brain. Pediatr Radiol 2011;41:1284-92

52. Sie LT, Hart AA, van Hof J, et al. Predictive value of neonatal MRI with respect to late MRI findings and clinical outcome: a study in infants with periventricular densities on neonatal ultrasound. Neuropediatrics 2005;36:78-89

53. Munck P, Haataja L, Maunu J, et al. Cognitive outcome at 2 years of age in Finnish infants with very low birth weight born between 2001 and 2006. Acta Paediatr 2010;99:359-66

54. Woodward LJ, Edgin JO, Thompson D, et al. Object working memory deficits predicted by early brain injury and development in the preterm infant. Brain 2005;128:2578-87

55. Spittle AJ, Treyvaud K, Doyle LW, et al. Early emergence of behavior and social-emotional problems in very preterm infants. $\mathrm{J} \mathrm{Am}$ Acad Child Adolesc Psychiatry 2009;48:909-18

56. Edgin JO, Inder TE, Anderson PJ, et al. Executive functioning in preschool children born very preterm: relationship with early white matter pathology. J Int Neuropsychol Soc 2008;14:90-101

57. Woodward LJ, Clark CA, Pritchard VE, et al. Neonatal white matter abnormalities predict global executive function impairment in children born very preterm. Dev Neuropsychol 2011;36:22-41

58. Clark CA, Woodward LJ. Neonatal cerebral abnormalities and later verbal and visuospatial working memory abilities of children born very preterm. Dev Neuropsychol 2010;35:622-42

59. Iwata S, Nakamura T, Hizume E, et al. Qualitative brain MRI at term and cognitive outcomes at 9 years after very preterm birth. Pediatrics 2012;129:e1138-47

60. Reidy N, Morgan A, Thompson DK, et al. Impaired language abilities and white matter abnormalities in children born very preterm and/or very low birth weight. J Pediatr 2013;162:719-24

61. Iwata S, Iwata O, Bainbridge A, et al. Abnormal white matter appearance on term FLAIR predicts neuro-developmental outcome at 6 years old following preterm birth. Int J Dev Neurosci 2007;25:523-30

62. de Bruïne FT, Van Den Berg-Huysmans AA, Leijser LM, et al. Clinical implications of MR imaging findings in the white matter in very preterm infants: a 2-year follow-up study. Radiology 2011;261: 899-906

63. Kidokoro H, Anderson PJ, Doyle LW, et al. High signal intensity on T2-weighted MR imaging at term-equivalent age in preterm infants does not predict 2-year neurodevelopmental outcomes. AJNR Am J Neuroradiol 2011;32:2005-10

64. Hagmann CF, De Vita E, Bainbridge A, et al. T2 at MR imaging is an objective quantitative measure of cerebral white matter signal intensity abnormality in preterm infants at term-equivalent age. $R a$ diology 2009;252:209-17

65. Papile LA, Burstein J, Burstein R, et al. Incidence and evolution of subependymal and intraventricular hemorrhage: a study of infants with birth weights less than 1,500 gm. I Pediatr 1978;92:529-34

66. Jary S, De Carli A, Ramenghi LA, et al. Impaired brain growth and neurodevelopment in preterm infants with posthaemorrhagic ventricular dilatation. Acta Paediatr 2012;101:743-48

67. De Vries LS, Groenendaal F, van Haastert IC, et al. Asymmetrical myelination of the posterior limb of the internal capsule in infants with periventricular haemorrhagic infarction: an early predictor of hemiplegia. Neuropediatrics 1999;30:314-19

68. Horsch S, Kutz P, Roll C. Late germinal matrix hemorrhage-like lesions in very preterm infants. J Child Neurol 2010;25:809-14

69. Lind A, Lapinleimu H, Korkman M, et al. Five-year follow-up of prematurely born children with postnatally developing caudothalamic cysts. Acta Paediatr 2010;99:304-07

70. Drobyshevsky A, Bregman J, Storey P, et al. Serial diffusion tensor imaging detects white matter changes that correlate with motor outcome in premature infants. Dev Neurosci 2007;29:289-301

71. Glass HC, Berman JI, Norcia AM, et al. Quantitative fiber tracking of the optic radiation is correlated with visual-evoked potential 
amplitude in preterm infants. AJNR Am J Neuroradiol 2010;31:1424-29

72. van Kooij BJ, De Vries LS, Ball G, et al. Neonatal tract-based spatial statistics findings and outcome in preterm infants. AJNR Am J Neuroradiol 2012;33:188-94

73. Krishnan ML, Dyet LE, Boardman JP, et al. Relationship between white matter apparent diffusion coefficients in preterm infants at term-equivalent age and developmental outcome at 2 years. Pediatrics 2007;120:e604-09

74. van Kooij BJ, Van Pul C, Benders MJ, et al. Fiber tracking at term displays gender differences regarding cognitive and motor outcome at 2 years of age in preterm infants. Pediatr Res 2011;70:626-32

75. Rogers CE, Anderson PJ, Thompson DK, et al. Regional cerebral development at term relates to school-age social-emotional development in very preterm children. J Am Acad Child Adolesc Psychiatry 2012;51:181-91

76. Boardman JP, Craven C, Valappil S, et al. A common neonatal image phenotype predicts adverse neurodevelopmental outcome in children born preterm. Neuroimage 2010;52:409-14

77. Kaukola T, Perhomaa M, Vainionpaa L, et al. Apparent diffusion coefficient on magnetic resonance imaging in pons and in corona radiata and relation with the neurophysiologic measurement and the outcome in very preterm infants. Neonatology 2010;97:15-21

78. Rose J, Butler EE, Lamont LE, et al. Neonatal brain structure on MRI and diffusion tensor imaging, sex, and neurodevelopment in very-low-birthweight preterm children. Dev Med Child Neurol 2009;51:526-35

79. Arzoumanian Y, Mirmiran M, Barnes PD, et al. Diffusion tensor brain imaging findings at term-equivalent age may predict neurologic abnormalities in low birth weight preterm infants. AJNR Am J Neuroradiol 2003;24:1646-53

80. Bassi L, Ricci D, Volzone A, et al. Probabilistic diffusion tractography of the optic radiations and visual function in preterm infants at term equivalent age. Brain 2008;131:573-82

81. Dubois J, Benders M, Borradori-Tolsa C, et al. Primary cortical folding in the human newborn: an early marker of later functional development. Brain 2008;131:2028-41

82. Kapellou O, Counsell SJ, Kennea N, et al. Abnormal cortical development after premature birth shown by altered allometric scaling of brain growth. PLoS Med 2006;3:e265

83. Rathbone R, Counsell SJ, Kapellou O, et al. Perinatal cortical growth and childhood neurocognitive abilities. Neurology 2011;77:1510-17

84. Badr LK, Bookheimer S, Purdy I, et al. Predictors of neurodevelopmental outcome for preterm infants with brain injury: MRI, medical and environmental factors. Early Hum Dev 2009;85:279-84

85. Tan M, Abernethy L, Cooke R. Improving head growth in preterm infants: a randomised controlled trial II: MRI and developmental outcomes in the first year. Arch Dis Child Fetal Neonatal Ed 2008;93:f342-46

86. Lind A, Parkkola R, Lehtonen L, et al. Associations between regional brain volumes at term-equivalent age and development at 2 years of age in preterm children. Pediatr Radiol 2011;41:953-61

87. Lind A, Haataja L, Rautava L, et al. Relations between brain volumes, neuropsychological assessment and parental questionnaire in prematurely born children. Eur Child Adolesc Psychiatry 2010;19:407-17

88. Shah DK, Anderson PJ, Carlin JB, et al. Reduction in cerebellar volumes in preterm infants: relationship to white matter injury and neurodevelopment at two years of age. Pediatr Res 2006;60:97-102

89. van Kooij BJ, Benders MJ, Anbeek P, et al. Cerebellar volume and proton magnetic resonance spectroscopy at term, and neurodevelopment at 2 years of age in preterm infants. Dev Med Child Neurol 2012;54:260-66

90. Peterson BS, Anderson AW, Ehrenkranz R, et al. Regional brain volumes and their later neurodevelopmental correlates in term and preterm infants. Pediatrics 2003;111:939-48

91. Gadin E, Lobo M, Paul DA, et al. Volumetric MRI and MRS and early motor development of infants born preterm. Pediatr Phys Ther 2012;24:38-44

92. Shah DK, Guinane C, August P, et al. Reduced occipital regional volumes at term predict impaired visual function in early childhood in very low birth weight infants. Invest Ophthalmol Vis Sci 2006;47:3366-73

93. Thompson DK, Wood SJ, Doyle LW, et al. Neonate hippocampal volumes: prematurity, perinatal predictors, and 2-year outcome. Ann Neurol 2008;63:642-51

94. Beauchamp MH, Thompson DK, Howard K, et al. Preterm infant hippocampal volumes correlate with later working memory deficits. Brain 2008;131:2986-94

95. Valkama AM, Tolonen EU, Kerttula LI, et al. Brainstem size and function at term age in relation to later neurosensory disability in high-risk, preterm infants. Acta Paediatr 2001;90:909-15

96. Maunu J, Lehtonen L, Lapinleimu H, et al. Ventricular dilatation in relation to outcome at 2 years of age in very preterm infants: a prospective Finnish cohort study. Dev Med Child Neurol 2011;53:48-54

97. Tich SN, Anderson PJ, Hunt RW, et al. Neurodevelopmental and perinatal correlates of simple brain metrics in very preterm infants. Arch Pediatr Adolesc Med 2011;165:216-22

98. Spittle AJ, Doyle LW, Anderson PJ, et al. Reduced cerebellar diameter in very preterm infants with abnormal general movements. Early Hum Dev 2010;86:1-5

99. Thayyil S, Chandrasekaran M, Taylor A, et al. Cerebral magnetic resonance biomarkers in neonatal encephalopathy: a meta-analysis. Pediatrics 2010;125:e382-95

100. Nossin-Manor R, Chung AD, Whyte HEA, et al. Deep gray matter maturation in very preterm neonates: regional variations and pathology-related age-dependent changes in magnetization transfer ratio. Radiology 2012;263:510-17

101. Smyser CD, Inder TE, Shimony JS, et al. Longitudinal analysis of neural network development in preterm infants. Cereb Cortex 2010;20:2852-62

102. Doyle LW. Antenatal magnesium sulfate and neuroprotection. Curr Opin Pediatr 2012;24:154-59

103. Rees S, Harding R, Walker D. The biological basis of injury and neuroprotection in the fetal and neonatal brain. Int J Dev Neurosci 2011;29:551-63

104. Jones DK, Cercignani M. Twenty-five pitfalls in the analysis of diffusion MRI data. NMR Biomed 2010;23:803-20

105. Pannek K, Guzzetta A, Colditz PB, et al. Diffusion MRI of the neonate brain: acquisition, processing and analysis techniques. Pediatr Radiol 2012 42:1169-82

106. De Vries LS, Van Haastert IL, Rademaker KJ, et al. Ultrasound abnormalities preceding cerebral palsy in high-risk preterm infants. J Pediatr 2004;144:815-20

107. Horsch S, Skiold B, Hallberg B, et al. Cranial ultrasound and MRI at term age in extremely preterm infants. Arch Dis Child Fetal Neonatal Ed 2010;95:F310-14 